\section{Neoconservadurismo: modelo de la política cultural del Estado en la Zona Metropolitana de Guadalajara}

Introducción

Modelo cultural es un concepto que sirve para reconocer y describir la mentalidad y las estrategias de poder que distinguen a una agrupación social en un contexto determinado. Cultura política es la mentalidad que da sentido a las

Mediante el análisis estructural de contenido, y la descripción de las prácticas, el artículo explora los planes de desarrollo y los informes de gobierno del periodo 2010-20I2 de los municipios que integran la Zona Metropolitana de Guadalajara (ZMG). El propósito es develar la filosofía y las prácticas que dan forma y sentido a la política cultural del Estado, la cual sigue un modelo cultural implícito y explícito que es análogo al neoconservadurismo. La cultura política y las estrategias para promover la democracia y la diversidad cultural de forma sistemática persisten como dispositivos de exclusión social de muchos ciudadanos, entre los que se encuentran los artesanos, y los no ciudadanos que forman parte de la cultura popular.

Palabras clave: neoconservadurismo, política cultural del Estado, cultura política, democracia, diversidad cultural.

- Investigador independiente eduardoplazola@yahoo.com.mx estrategias de poder de la política cultural. Las prácticas de las políticas culturales son las tácticas de poder de la cultura política. Así, la relación de ambas -cultura política y práctica cultural- es lo que hace congruente y coherente el modelo cultural.

La mentalidad y las estrategias de la política cultural del Estado en la Zona Metropolitana de Guadalajara (ZMG) ${ }^{1}$ durante el periodo 2010-2012 resultaron excluyentes, análogas al modelo cultural neoconservador, el cual se distingue por centralizar el poder y sofocar la diversidad cultural. Las prácticas dirigidas y la cultura política

I. Los municipios que integran la ZMG son Guadalajara, Zapopan, San Pedro Tlaquepaque, Tonalá y Tlajomulco de Zuñiga. Todos pertenecen al estado de Jalisco, México.

Espiral, Estudios sobre Estado y Sociedad

Vol. xxı No. 60 \ayo / Agosto de 2014 
de las instituciones del Estado que son responsables de la política cultural de los diversos municipios promovieron la negación del derecho a la cultura, en el marco del discurso de la democracia y la diversidad cultural.

La motivación de este artículo es contribuir con información sistemática y actual sobre el modelo cultural del Estado, en materia de política cultural, ${ }^{2}$ un terreno relativamente poco explorado en la ZMG. Para conseguirlo, conviene analizar estructuralmente el discurso y caracterizar las prácticas en torno a la democracia y a la diversidad cultural, para así establecer relaciones con el modelo cultural neoconservador. La identificación del modelo implícito y explícito de la política cultural es una forma de sistematizar lo que dicen y hacen las instituciones estatales; un ejercicio pertinente ante las posibles prácticas de democracia representativa y negación de la diversidad; con la intención de ampliar las posibilidades para diseñar y poner en acción otras formas de usar el poder, y vivir junto a otros en un espacio común.

El presente artículo se divide en cuatro apartados: i) la política cultural del Estado en México y en Jalisco de 1998 a 2006, donde busco señalar las relaciones de esta política con el neoconservadurismo; ii) las estrategias de la política cultural del Estado en la ZMG de 2010 a 2012, donde incluyo la caracterización de las acciones de los diferentes municipios para promover otras identidades y formas de arte; iii) la cultura política de la política cultural del Estado en la ZMG, donde llevo a cabo un análisis estructural de los conceptos participación ciudadana y derecho a la cultura; y iv) las conclusiones.

2. Además de presentar información reciente, este texto abarca el periodo 20102012, durante el cual el Partido Revolucionario Institucional (PRI) desplazó, en casi todos los ayuntamientos de la ZMG, al Partido Acción Nacional (PAN), el cual había gobernado con mayoría en los últimos 15 años en la Zona Metropolitana. 
Neoconservadurismo: modelo de la política cultural del Estado en la Zona

Metropolitana de Guadalajara

La política cultural del Estado en México y en Jalisco

de 1998 a 2006

Las políticas culturales tienen relación con los modelos culturales, es decir, con las "cosmovisiones colectivas" y las "construcciones sociales" de la realidad (Muñoz, 2005: 13). Modelo cultural es un marco analítico que funciona para ubicar las concepciones que resultan valiosas (cosmovisión) y la acción social válida (la realidad construida por la acción social de los sujetos) en un contexto particular. Muñoz (2005: 17) sostiene que "cada concepción económica y política erige un modelo de lo que debe ser la cultura en el que se refleja no sólo la mentalidad del grupo, sino ante todo las estrategias de control social y asimilación de la población en los valores dominantes".

En sí mismo, el Estado puede ser percibido como modelo cultural, esto es, como una idea genérica acerca de qué es la sociedad y cómo vivir en ella, junto con una serie de prácticas estratégicas que legitiman sus ideas ante la población que legisla. Las instituciones del Estado sostienen la mentalidad de la democracia ${ }^{3}$ y la unidad nacional y, entre otras prácticas, ponen en acción la política pública como dispositivo para asimilar y controlar a la ciudadanía nacional. Uno de los dispositivos de poder del Estado es la política cultural, mediante la cual propaga los valores acerca

3. Defino la democracia como una forma de hacer política y de darle sentido al uso social del poder que se basa en la búsqueda de la libertad, la igualdad, el orden y la participación social. A lo largo del tiempo, la interpretación de la democracia por parte de las instituciones del Estado ha fomentado entre las y los ciudadanos la libertad de elegir los políticos, propagado el desarrollo como ideal de la igualdad social, impuesto el orden a través de dispositivos coercitivos como los aparatos de seguridad pública, y defendido la idea del derecho. En la ZMG hay distintos modelos de la democracia (como la propuesta por "los de abajo" (cfr. Alonso y Ramírez, 1997) y otros tantos que la niegan y proponen alternativas a ella (como los colectivos skinheads y anarquistas que se agrupan en el tianguis cultural); la democracia que propone el Estado es solamente un modelo entre muchos otros, que también implica contradicciones y está en constante reinterpretación y reingeniería, hasta que la crítica logre destruirlo y se abran alternativas frente a él. 
del arte, la filosofía, la ciencia y las relaciones sociales, activando así estrategias de integración y ordenamiento, tales como la educación, la legislación, el financiamiento a la producción de obras y el acercamiento de los bienes y servicios públicos.

Antes de la década de los cincuenta del siglo pasado, el modelo cultural mexicano tenía relación con el Estado benefactor. ${ }^{4}$ Las instituciones de este tipo de Estado enfocaban las actividades de la -aún no declarada- política cultural en la educación "formal", a manera de socialización, y en las "bellas artes", a modo de mecanismo de aculturación, tal cual se muestra en los casos de la educación nacionalista en México y el "difusionismo" (Mariscal, 2007). Varias décadas después, durante los años ochenta, a nivel internacional y en México se conformaron subinstituciones de Estado especializadas en temas no solamente de la ciencia (educación formal), sino enfocadas, a través de programas y proyectos particulares de desarrollo, en la promoción y aprendizaje del arte, la difusión de los derechos culturales y la valoración y el uso del patrimonio. Su objetivo era generar bienestar y calidad de vida para los diversos ciudadanos. No es casualidad que el Consejo Nacional para la Cultura y las Artes (CONACULTA) se haya creado en esta época (1989). Tampoco sorprende saber que la última década del siglo XX haya sido declarada por la UNESCO como el "decenio de la cultura", periodo cuando la Secretaria de Cultura Jalisco expandió sus operaciones. ${ }^{5}$

4. El Estado benefactor es un enfoque y una forma de ingeniería social en la historia del Estado. Siguiendo la caracterización que hace Barba (2005: 38-42) del paradigma "corporativo" de la política social, el Estado Benefactor se caracteriza por burocratizar las relaciones sociales, subsidiar y asistir a la sociedad en materia de desarrollo, centralizar y estabilizar el poder en ciertas clases sociales, buscar la integración nacional (nación $=$ polis) a través de la violencia institucional, usar la economía capitalista y navegar en la paradoja autoritarismo/democracia.

5. La Secretaría de Cultura Jalisco surgió en 1992. Antes, entre 1989 y 1992 , la dependencia responsable de la política cultural estatal era la Secretaría de 
Neoconservadurismo: modelo de la política cultural del Estado en la Zona

Metropolitana de Guadalajara

Según la Convención sobre la Protección y Promoción de la Diversidad de las Expresiones Culturales (UNESCO, 2005: 4), las políticas culturales de cualquier Estado tendrían el fin de "ejercer un efecto directo en las expresiones culturales de las personas, grupos o sociedades, en particular la creación, producción, difusión y distribución de las actividades y los bienes y servicios culturales y el acceso a ellos". Nivón (2006a: 23) afirma que la política cultural del Estado mexicano es "regulatoria", y que a lo largo del tiempo se han presentado tres contradicciones entre sus ideas y sus prácticas: "la que se da entre la universalidad y la particularidad de la cultura, la que define la autonomía o subordinación del arte o los artistas, y la que tiene que ver con nuestro modelo de organización estatal y la democracia”. Algunos años atrás durante el periodo de 1998 a 2003 Castro de la Mora (2010: 403-413) había llegado a conclusiones semejantes para el caso de Jalisco. El centro de atención de su trabajo lo recibió el análisis de las políticas culturales de descentralización, desde la "lógica del bienestar". Su conclusión fue que "hoy por hoy, en la Constitución del Estado de Jalisco, el derecho a la cultura no tiene reconocimiento [...] la institución cultural del municipio y los habitantes del mismo, fueron conducidos por la imposición central a seguir las líneas marcadas por el gobierno estatal”.

Según las consideraciones de ambos autores, la idea de la democracia fue tergiversada a través de las prácticas "centralistas" y "contradictorias" de las políticas culturales de los diversos órdenes de gobierno. En Jalisco y a nivel nacional el Estado desplegó la mentalidad elitista y las prácticas excluyentes que caracterizan al "neoconservadurismo"

Educación y Cultura. Entre 1971 y 1983 no había instituciones culturales en forma de secretaría en el gobierno de Jalisco; había otros organismos como el Departamento de Bellas Artes (197I) y el Instituto Cultural Cabañas (1980), entre otros, así como programas sociales como el Fondo Nacional para las Actividades Sociales y Culturales (1977-1983) (cfr. Castro de la Mora, 2010). 
(Muñoz, 2005: 70): un tipo de modelo cultural ${ }^{6}$ en el que "la cultura [es] entendida como orden y tradición [...] frente a otros conceptos de cultura más cercanos y centrados en la defensa de los ideales ilustrados y sus influencias sobre un modelo de democracia social y cívica". El modelo cultural neoconservador ostenta las siguientes características:

I. Se excluyen otras formas culturales; la cultura es entendida como jerarquía y disciplina; aparecen estilos de vida que unifican las conductas y los códigos sociales diferentes; y se proclama el fin de las ideologías, así como la vuelta a un pasado intemporal.

2. La centralización del poder; hay pocas posibilidades de establecer un espacio para el intercambio de ideas, la libre discusión y la creación independiente, sin que haya consecuencias indeseadas.

3. La filosofía conservadora está presente; se enfatiza la teoría del "mal metafísico", es decir, la creencia de que el orden social desigual es 'natural' e inútil es su cuestionamiento, y la reformulación del modelo orgánico-evolucionista spenceriano (teoría vetusta del desarrollo, basada en la caridad y la protección social).

Las contradicciones de la política cultural del Estado en México alientan la exclusión y la centralización del poder característicos del neoconservadurismo. En Jalisco la situación es parecida, ya que las ideas y las prácticas de las instituciones que decretan políticas culturales "confunden

6. En 1987 García Canclini propuso tipificar los diferentes enfoques de la política cultural del Estado en varios países de América Latina. Quizá los tipos "tradicionalismo patrimonialista", “democratización cultural” y "estatismo populista” no estén tan alejados del modelo cultural "neoconservador". El primero fomenta la identidad nacional y la preservación del folclor; el segundo pretende la difusión y la popularización de la alta cultura y el acceso a los bienes culturales; mientras que el último pretende reivindicar y controlar la cultura popular y difundir el acceso a la cultura. En el fondo, el neoconservadurismo pretende el impulso del nacionalismo, la alta cultura, los derechos y el "desarrollo cultural", pero sin posibilitar que la cultura popular tenga mayor incidencia en la forma en la que se definen esos temas y en el impulso de otros relacionados con la cultura popular; todo lo cual resulta una contradicción frente a la democracia participativa y las demandas por el reconocimiento de la diversidad cultural. 
Neoconservadurismo: modelo de la política cultural del Estado en la Zona

Metropolitana de Guadalajara

los conceptos de diferencia de capacidades y aptitudes con desigualdades sociales, económicas, políticas y culturales" (Muñoz, 2005: 89). Las políticas culturales del gobierno federal y del estado de Jalisco se rigen por la mentalidad de la democracia y el progreso, pero sus dispositivos de poder limitan el derecho a la cultura y aparentan promover el "mal metafísico", es decir, la sofocación de la crítica y la represión de los movimientos sociales que ponen en riesgo las posiciones de poder de las instituciones del Estado. El modelo de este tipo de políticas culturales no pretende la participación activa de los ciudadanos en la toma de decisiones y en el uso de los recursos públicos, tampoco busca el reconocimiento de la diversidad cultural $^{7}$ ni el acceso universal al "desarrollo cultural". En todo caso, se deja ver el padecimiento de "la contradicción de las heridas abiertas del pasado, la infección de prácticas ciudadanas que, a su vez, reflejan prácticas culturales nefastas; una gestión cultural desarticulada e improvisada, anémica” (Lozano, 2009: 9).

Ahora, varios años después, el modelo neoconservador de las políticas culturales del Estado parece tener eco en el discurso y en las estrategias de la política cultural municipal, particularmente las que se observan en la Zona Metropolitana de Guadalajara.

7. Diversidad cultural tiene que ver con igualdad y respeto de las diferencias de identidad, así como con los procesos sociales de interculturalidad; es decir, con la tensa interacción entre diferentes sujetos y agrupaciones sociales con identidad propia. Cervantes (en Frisancho et ál., 2006:43) afirma que el tema de la diversidad cultural hace referencia a que "la cultura es un concepto comparativo y el hecho de que existan tantas formas de interpretar el fenómeno de la pluralidad cultural tiene que ver con que la cultura es una práctica colectiva”. En el fondo, tiene relación con el llamado que hace Todorov (20II) para "aprender a vivir con los otros", y para construir espacios con condiciones de vida digna para todos y todas, en los que el egocentrismo, el nacionalismo y el cientificismo no conduzcan al exterminio. En su aspecto político, la diversidad cultural tiene relación con los procesos de “desarrollo cultural”, emprendidos principalmente por la UNESCO (cfr. Declaración Universal de la Diversidad Cultural, 200I) para investigar e incidir por medio de políticas públicas en la promoción del patrimonio, el pluralismo, los derechos de todas las generaciones y la creatividad. 
Las estrategias de la política cultural del Estado en la ZMG de 2010 a 2012

La política cultural del Estado en la ZMG del último trienio parece haber ido en sintonía con lo hecho a nivel estatal y federal. En los municipios, las políticas culturales del Estado utilizaron estrategias que poco alentaron la justicia social y la promoción de la diversidad cultural, sin presentar mayor información de sus acciones, valores e impactos. En este apartado voy a detenerme en la caracterización de las estrategias de poder de la política cultural de las direcciones, institutos y secretarías de los municipios que conforman la ZMG, para establecer su relación con el modelo cultural neoconservador. Entre las numerosas actividades que realizan los ayuntamientos municipales en materia de cultura, únicamente atenderé a las que se llevaron a cabo para promover la democracia y la diversidad cultural. ${ }^{8}$

Para comenzar el análisis, revisaré las acciones que fueron reportadas en los informes de gobierno correspondientes a los años 2010, 2011 y $2012,{ }^{9}$ utilizando la matriz

8. Del modo en que esto quedó expresado en las notas al pie tres y siete.

9. Antes de entrar de lleno en la descripción de las actividades de la política cultural del Estado, es pertinente señalar algunos de los objetivos en este renglón de los diferentes municipios, plasmados en los planes de desarrollo. En el municipio de Tlajomulco puede leerse que la pretensión era una "política cultural para todos que garantice el acceso a la cultura, el deporte y la recreación" $(2010,34)$. En Tonalá afirman que la política cultural buscaría "fomentar la diversidad cultural en las distintas colonias y comunidades del municipio" $(2010,30)$. El programa Red, de la Secretaría de Cultura Guadalajara, intentaría la "atención cultural descentralizada en colonias y barrios de la ciudad, que permita desarrollar un mapa territorialmente equilibrado de las actividades culturales a efecto de integrar a las diversas zonas y colonias del municipio a una lógica de desarrollo cultural, artístico y de participación" (2010, 144). El Instituto de Cultura de Zapopan aspiraba a "crear talleres artesanales comunales permanentes, en los que las mujeres adquieran habilidades en alfarería, bordado, costura, agricultura doméstica, entre otros, y proporcionar también a estas mujeres microcréditos para que inicien un negocio familiar" $(2010,82)$. En Tlaquepaque la propuesta era "promover la capacitación en los artesanos para la mejora de sus procesos de fabricación y conservación de las técnicas artesanales" $(2010,53)$. Directa o indirectamente, todos los objetivos apuntan hacia la aparente democratización de la cultura e integración 
Neoconservadurismo: modelo de la política cultural del Estado en la Zona

Metropolitana de Guadalajara

de información para ordenar los datos (véase el cuadro 1). La diversidad cultural será valorada a partir de la descripción de las acciones para reconocer, difundir y proteger las prácticas culturales distintas al modelo cultural del Estado. Las acciones para lograr la democracia van a ser analizadas considerando lo que se ha hecho para alentar la participación ciudadana, ${ }^{10}$ es decir, para promover mecanismos cuyo propósito sea lograr que los ciudadanos influyan en la toma de decisiones y en el uso de los recursos de las instituciones estatales, especialmente las relacionadas con la política cultural.

Resulta difícil sintetizar los múltiples indicadores que utilizan las instituciones municipales para analizar la política cultural. Las mediciones varían de una dependencia a otra e incluso de un año a otro; además, en algunos casos se repite la información en diferentes periodos. El tema de la cultura, en lo particular el referido a la diversidad cultural y a la democracia, no es prioritario en los informes de gobierno municipales, en todos los casos hay vacíos y escases de información, así como datos poco específicos, de los que no se explica cómo se elaboraron y que, por otra parte, denotan el manejo discrecional al respecto.

No obstante el posible sesgo de la información rescatada, podríamos deducir, en lo general, que las prácticas de las políticas culturales del Estado en la ZMG en materia de diversidad cultural y democracia son residuales, coyunturales, verticales, focalizadas e incongruentes. En el periodo descrito, la política cultural de cada municipio no generó condiciones permanentes de equidad e inclusión social para

social, pero hasta hoy desconocemos las estrategias y los impactos de esos propósitos, desde el punto de vista de los burócratas y de las y los beneficiarios. 10. Entiendo por participación ciudadana todas aquellas acciones y procesos que llevan a cabo los actores sociales que radican en algún territorio administrado por el Estado, con la intención de incidir en el destino de la política pública gubernamental, así como en las instituciones en las que se toman las decisiones sobre los asuntos públicos y en el discurso que orienta esas acciones y procesos. 
Cuadro 1. Prácticas de diversidad cultural y democracia de la política cultural del Estado en la ZMG (2010-2012)

\begin{tabular}{|c|c|c|c|c|c|}
\hline Rubro & Guadalajara & Zapopan & Tlaquepaque & Tlajomulco & Tonalá \\
\hline $\begin{array}{l}\text { Actividades } \\
\text { para } \\
\text { promover } \\
\text { otras } \\
\text { prácticas } \\
\text { culturales }\end{array}$ & $\begin{array}{l}\text { Financia- } \\
\text { miento } \\
\text { de eventos } \\
\text { y proyectos } \\
\text { de difusión, } \\
\text { equipamiento } \\
\text { de espacios, } \\
\text { educación }\end{array}$ & $\begin{array}{l}\text { Financia- } \\
\text { miento } \\
\text { de eventos, } \\
\text { promoción de } \\
\text { patrimonio } \\
\text { intangible, } \\
\text { educación }\end{array}$ & $\begin{array}{l}\text { Financia- } \\
\text { miento de } \\
\text { eventos, } \\
\text { educación, } \\
\text { equipamiento } \\
\text { de espacios }\end{array}$ & $\begin{array}{l}\text { Financia- } \\
\text { miento } \\
\text { de eventos, } \\
\text { impulso } \\
\text { al turismo } \\
\text { cultural, } \\
\text { educación }\end{array}$ & $\begin{array}{l}\text { Financia- } \\
\text { miento de } \\
\text { proyectos } \\
\text { de } \\
\text { desarrollo } \\
\text { cultural, } \\
\text { educación }\end{array}$ \\
\hline $\begin{array}{l}\text { Actividades } \\
\text { para } \\
\text { alentar la } \\
\text { participación } \\
\text { ciudadana }\end{array}$ & $\begin{array}{l}\text { Educación } \\
\text { cívica, } \\
\text { transparencia }\end{array}$ & $\begin{array}{l}\text { Contacto con } \\
\text { líderes } \\
\text { vecinales, } \\
\text { transparencia }\end{array}$ & $\begin{array}{l}\text { Transpa- } \\
\text { rencia }\end{array}$ & $\begin{array}{l}\text { Reglamen- } \\
\text { tación } \\
\text { de prácticas, } \\
\text { descentra- } \\
\text { lización, } \\
\text { transparencia }\end{array}$ & $\begin{array}{l}\text { Conforma- } \\
\text { ción de } \\
\text { comités } \\
\text { vecinales, } \\
\text { transpa- } \\
\text { rencia }\end{array}$ \\
\hline
\end{tabular}

Fuente: elaboración propia con base en los informes municipales de gobierno de 2010, 2011 y 2012.

la diversidad de ciudadanos/as y los modelos culturales que integran la ciudad. Las estrategias para promover otras prácticas culturales redundaron en el escaso y selecto financiamiento: la educación enfocada en el aprendizaje de habilidades, y la difusión a través de eventos culturales de productos artísticos, costumbres y valores de -entre otras- la "cultura popular". ${ }^{11}$ Por el lado del fomento de la

II. Cultura popular significa la otra cara de la "alta cultura", basada ésta última en las bellas artes, la ciencia y las costumbres de la que se dio por llamar clase social "burguesa". La cultura popular se construye con artesanías y performance, saberes y creencias acientíficas, y con las prácticas significativas de, por ejemplo, los "pobres", los "indígenas" y los "altermundistas". Según los informes de gobierno de los municipios de la ZMG, estas fueron algunas actividades para promover la cultura popular: en Zapopan reportaron más de 35000 asistentes a talleres de arte y artesanía. El gobierno de Tlajomulco afirma que invirtieron 300000000 de pesos para el proyecto de turismo cultural en Cajititlán. En Tonalá se llevaron a cabo I 24 actividades de cultura popular, como la celebración de los Tastoanes. Tlaquepaque llevó a cabo 29 capacitaciones para artesanos entre 2010 y 20II. El municipio de Guadalajara no reporta información al respecto. La inversión, las actividades 
Neoconservadurismo: modelo de la política cultural del Estado en la Zona

Metropolitana de Guadalajara

participación ciudadana, las actividades tuvieron que ver con presentar información y procedimientos para transparentar los recursos y descentralizar la administración pública, además de la realización de esporádicas consultas ciudadanas por medio de encuestas y votaciones, ${ }^{12}$ y de los intentos no tan recurrentes para "legalizar" este tipo de participación social.

Las acciones para hacer efectiva la democracia quedaron en el nivel de la consulta, es decir, en pedir la opinión de algunos ciudadanos sobre asuntos públicos decididos, pero sin que esa opinión haya conseguido modificar las actividades previamente resueltas por los agentes del Estado. Transparentar el gasto público no es suficiente para que los habitantes de la ZMG tengan voz y voto en los espacios de poder de la política pública. Las agrupaciones de vecinos no tienen peso en las instituciones de gobierno. Los diversos ayuntamientos no presentan mecanismos concretos y permanentes para la participación ciudadana; situación que contraviene las pretensiones de la democracia participativa y la reduce a "democracia representativa elitista" (De Sousa, 2004: 39), en el estilo del nuevo conservadurismo que limita el uso social del poder y se legitima a sí mismo.

y los participantes en actividades de cultura popular son pocos, en relación con los potenciales beneficiarios y de acuerdo con el periodo de tiempo considerado. 12. En el año 20II, el municipio de Tlajomulco fue el primero en la ZMG en realizar una consulta de revocación de mandato del presiente municipal en la que participaron casi 18000 votantes, según el informe de gobierno de ese año. En Zapopan, en el año 2010 se informó que se realizaron poco más de 25000 consultas ciudadanas al respecto del Plan Municipal de Desarrollo. Ese mismo año, en el informe de gobierno de Tonalá se mencionó la realización de 3,300 consultas acerca del mismo tema. En Guadalajara, durante 2010 y 201 I se especifica en los informes de gobierno que mediante el programa Lunes Contigo fueron recibidas más de 44000 peticiones ciudadanas de bienes y servicios. En Tlaquepaque en ninguno de los informes se hace referencia a la participación ciudadana. Las acciones para que la democracia sea posible no parecen ser permanentes en los municipios, además esas prácticas no consiguen involucrar al grueso de las y los ciudadanos que habitan la ZMG. 
La diversidad cultural tampoco se consigue en el marco de la política cultural del Estado en la ZMG. Las estrategias para promover las costumbres y las percepciones de otras culturas no permean en la multiplicidad de identidades que construyen la ciudad, solamente son suficientes para apoyar económicamente a selectos artesanos. ${ }^{13}$ No todos los sectores de la población tienen derecho a espacios acondicionados para difundir la cultura o para conocer otros enfoques y formas de actuar en la ciudad. Los eventos culturales no bastan $^{14}$ y la educación promovida poco se concentra en socializar el respeto y la igualdad social, en conjunto con las habilidades para el arte. La política cultural del Estado en la ZMG no cuenta con estrategias precisas y dialogadas para que la cultura popular y otros modelos culturales sean reconocidos y alentados.

La política cultural del Estado en la ZMG en el periodo 2010-2012 sigue la trayectoria trazada desde tiempo atrás por la federación y el gobierno de Jalisco; aquella que reproduce las "contradicciones" señaladas por Nivón (2006a) y el "centralismo" enunciado por Castro de la Mora (2010). En sintonía con el modelo cultural neoconservador, las prácticas de la política cultural de los diferentes municipios manifestaron "un sentido de elitismo excluyente frente a

13. El municipio de Tonalá es el único que especifica en el informe de gobierno del año 2010 la inversión para la cultura popular, con programas como Artesano tu Confianza, entregaron cerca de I 800000 pesos para fomentar la producción y difusión de la alfarería de barro. Aunque no se menciona el tipo de apoyo otorgado, en Tlaquepaque tiene relevancia cada año la entrega del Premio Nacional de la Cerámica, una forma no tan directa de invertir en la cultura popular. 14. Los eventos culturales para difundir la cultura popular poco se hicieron, o no tuvieron espacio en los diferentes informes de gobierno de los municipios de la ZMG. En Tlajomulco se realizó la Expo Tlalliart, la cual en el año 20I I llevó a cabo II exposiciones para los artesanos del barro. Un año antes, en 2010 en Tlaquepaque se realizaron 19 exposiciones y ferias para los artesanos. En el periodo 20I0-20I I, en Tonalá se realizaron I 24 actividades culturales, como las fiestas religiosas tradicionales. Los municipios de Guadalajara y Zapopan no hacen mención en los informes de eventos culturales para difundir la cultura popular.

\section{4}


Neoconservadurismo: modelo de la política cultural del Estado en la Zona

Metropolitana de Guadalajara

lo popular y lo colectivo [...] adquiriendo un fuerte componente defensivo [...] una perspectiva de la sociedad y de la construcción histórica en las que la estática se sobrepone a la dinámica" (Muñoz, 2005: 65).

Dicho lo anterior, ahora presento el análisis de contenido de los informes de gobierno y de los planes de desarrollo 2010-2012 de los municipios que integran la ZMG, para así poder identificar la mentalidad y los valores acerca de la democracia y la diversidad cultural que sustentan las prácticas similares al neoconservadurismo de la política cultural del Estado que acabamos de revisar.

\section{La cultura política de la política cultural del Estado} en la ZMG

Las prácticas de la política cultural de Estado en la ZMG de los últimos años no son producto de la casualidad: son intencionales y están basadas en enfoques particulares del poder, las relaciones sociales, el arte y la cultura. Tejeda (en Castro y Tejeda, 2009: 27) emplea el concepto -que también usa como categoría- cultura política, el cual utiliza para deconstruir y nombrar las relaciones entre los significados y el uso social del poder. Según este autor, la cultura política es "una configuración particular de la pugna entre diferentes fuerzas sociales por establecer los significados hegemónicos de las relaciones sociales". Él propone estudiar la cultura de la política enfocándose en el análisis de las convicciones de fondo, los valores significativos y la atribución de significados presentados en las prácticas culturales.

Con imaginarios políticos, Tejeda, Ballesteros y González (en Castro, 2005) se refieren a la cultura política. Estos tienen que ver con las expectativas, las valoraciones, las concepciones y las utopías relacionadas al poder que ciertos actores expresan en particulares contextos. En similar sentido, pero con mayor profundidad analítica, Varela 
(2005: 166) define la cultura política como "el conjunto de signos y símbolos compartidos (transmiten conocimientos e información, portan valoraciones, suscitan sentimientos y emociones, expresan ilusiones y utopías) que afectan y dan significado a las estructuras de poder".

En sintonía con lo expuesto por los diversos autores y para fines de este estudio, entiendo por cultura política todos aquellos significados que dan coherencia y valor a las acciones de la política cultural, así como el sentido al modelo cultural de referencia. En esta parte del texto pretendo identificar el significado de la política cultural del Estado en la ZMG. Entre el océano de propuestas y justificaciones semánticas de las acciones contenidas en los informes de gobierno y los planes de desarrollo 2010-2012 retomaré las categorías usadas en el apartado anterior (democracia y diversidad cultural). Los indicadores que utilizaré son: para el caso de la categoría democracia, la participación ciudadana; en torno de la diversidad cultural, la cultura popular. A partir de los documentos oficiales y con base en las categorías e indicadores, extraje citas literales de los documentos oficiales (consúltese el cuadro 2) y las ordené para analizar su contenido.

A partir de las citas, puse en práctica las propuestas del “análisis estructural” del autor Hiernaux (en Suárez, 2008), pero no atendiendo los aspectos del placer y el deseo, sino su entender sociológico y cultural -aspecto poco manejado por el autor-. Básicamente, el análisis estructural tiene la intención de "remontarse, desde los materiales observados (manifestaciones) hasta los sistemas de sentido que encierran (contenidos), luego, de éstos a los modelos culturales que son sus formas socialmente típicas y, por fin, de estos últimos a las condiciones sociales que presiden su presencia, a su puesta en obra, a su persistencia o transformación" (Hiernaux, en Suárez, 2008: 74).

\section{6}


Neoconservadurismo: modelo de la política cultural del Estado en la Zona

Metropolitana de Guadalajara

Entonces, lo que hice fue seleccionar algunos sintagmas de las citas literales, luego los convertí en formas verbales y sustantivas simples, y de ahí busqué su antónimo, según se puede observar en el cuadro 2.

Cuadro 2. Disyunciones de la participación ciudadana y la cultura popular

\begin{tabular}{|c|c|c|c|c|}
\hline Ayuntamiento & $\begin{array}{l}\text { Participación } \\
\text { ciudadana }\end{array}$ & Disyunciones & Cultura popular & Disyunciones \\
\hline Tlajomulco & $\begin{array}{l}\text { "[...] se } \\
\text { reglamentaron } \\
\text { otras figuras } \\
\text { centrales de } \\
\text { participación } \\
\text { ciudadana como la } \\
\text { consulta popular } \\
\text { y la iniciativa } \\
\text { ciudadana" } \\
\text { (Ayuntamiento de } \\
\text { Tlajomulco, 2011: } \\
\text { 26) }\end{array}$ & $\begin{array}{l}\text { Reglamentar/ } \\
\text { desordenar }\end{array}$ & $\begin{array}{l}\text { "Nuestros objetivos } \\
\text { serán conformar } \\
\text { una red de artistas } \\
\text { y artesanos } \\
\text { del municipio" } \\
\text { (Ayuntamiento de } \\
\text { Tlajomulco, 2010b: } \\
\text { 40) }\end{array}$ & $\begin{array}{l}\text { Artistas / } \\
\text { artesanos }\end{array}$ \\
\hline Tlaquepaque & $\begin{array}{l}\text { "[..] derecho } \\
\text { básico de la } \\
\text { ciudadanía de } \\
\text { saber y tener } \\
\text { certidumbre en } \\
\text { torno a la gestión } \\
\text { del gobierno" } \\
\text { (Ayuntamiento } \\
\text { de Tlaquepaque, } \\
\text { 2010b: 9) }\end{array}$ & $\begin{array}{l}\text { Derecho/ } \\
\text { desorden }\end{array}$ & $\begin{array}{l}\text { "Promover la } \\
\text { capacitación en } \\
\text { los artesanos } \\
\text { para la mejora } \\
\text { de sus procesos } \\
\text { de fabricación y } \\
\text { conservación de las } \\
\text { técnicas artesanales" } \\
\text { (Ayuntamiento de } \\
\text { Tlaquepaque, 2010b: } \\
\text { 53) }\end{array}$ & $\begin{array}{l}\text { Capaz /inútil } \\
\text { Artesanía/ } \\
\text { arte } \\
\text { Conservar/ } \\
\text { olvidar }\end{array}$ \\
\hline Tonalá & $\begin{array}{l}\text { “[...] conformamos } \\
\text { por primera } \\
\text { vez en Tonalá, } \\
\text { la Contraloría } \\
\text { Social Municipal" } \\
\text { (Ayuntamiento de } \\
\text { Tonalá, 2011: 27) }\end{array}$ & $\begin{array}{l}\text { Contraloría/ } \\
\text { ilegalidad }\end{array}$ & $\begin{array}{l}\text { "[...] llevamos a cabo } \\
92 \text { actividades de } \\
\text { culturas populares, } \\
\text { como la presentación } \\
\text { de las jugadas de } \\
\text { los tastoanes y la } \\
\text { danza de Viejos del } \\
\text { Martes de Carnaval" } \\
\text { (Ayuntamiento de } \\
\text { Tonalá, 2011: } 60 \text { ) }\end{array}$ & $\begin{array}{l}\text { Popular/ } \\
\text { culto }\end{array}$ \\
\hline
\end{tabular}




\begin{tabular}{|c|c|c|c|c|}
\hline Zapopan & $\begin{array}{l}\text { "[...] propósito de } \\
\text { crear cohesión } \\
\text { social, de } \\
\text { involucrar a la } \\
\text { ciudadanía en la } \\
\text { construcción de } \\
\text { su propio entorno } \\
\text { y de generar } \\
\text { participación social } \\
\text { en el municipio" } \\
\text { (Ayuntamiento de } \\
\text { Zapopan, 2011: 45) }\end{array}$ & $\begin{array}{l}\text { Cohesionar/ } \\
\text { desintegrar }\end{array}$ & $\begin{array}{l}\text { "Crear talleres } \\
\text { artesanales } \\
\text { comunales } \\
\text { permanentes, } \\
\text { en los que las } \\
\text { mujeres adquieran } \\
\text { habilidades en } \\
\text { alfarería, bordado, } \\
\text { costura, agricultura } \\
\text { doméstica, entre } \\
\text { otros y proporcionar } \\
\text { también a } \\
\text { estas mujeres } \\
\text { microcréditos" } \\
\text { (Ayuntamiento de } \\
\text { Zapopan, 2010b: 43) }\end{array}$ & $\begin{array}{l}\text { Generar/ } \\
\text { desorganizar }\end{array}$ \\
\hline Guadalajara & $\begin{array}{l}\text { "Para fomentar } \\
\text { una cultura cívica } \\
\text { de responsabilidad } \\
\text { y formar mejores } \\
\text { ciudadanos..." } \\
\text { (Ayuntamiento } \\
\text { de Guadalajara, } \\
\text { 2010a: 8) }\end{array}$ & $\begin{array}{l}\text { Cívico/ } \\
\text { incívico } \\
\text { Responsable/ } \\
\text { incompetente } \\
\text { Mejor/peor }\end{array}$ & $\begin{array}{l}\text { "A nuestra } \\
\text { comunidad artística } \\
\text { la apoyamos con } \\
\text { más de } 9 \text { millones } \\
\text { de pesos a través de } \\
\text { diversos programas" } \\
\text { (Ayuntamiento de } \\
\text { Guadalajara, 2010a: } \\
\text { 14) }\end{array}$ & $\begin{array}{l}\text { Artístico/no } \\
\text { artístico }\end{array}$ \\
\hline
\end{tabular}

Fuente: elaboración propia con base en el los informes de gobiernos y los planes de desarrollo de cada municipio.

Las citas elegidas de los informes y los planes de desarrollo las utilicé para "identificar las disyunciones elementales en cuyo seno cada una de estas unidades adquiere su sentido propio al demarcarse de lo que 'no es ella' [para luego] verificar las asociaciones entre unidades y términos de una pareja de contradefiniciones y las otras" (Hiernaux, en Suárez, 2008: 78). Una vez identificadas las disyunciones de cada forma verbal o sustantiva (antónimo del sintagma elegido de las citas de los informes de gobierno y los planes de desarrollo), proseguí con la verificación del significado de cada una de ellas para descubrir el contenido con el que estaban asociados y deducir, a partir de esos significados, el modelo cultural implícito en cada manifestación discursiva. 
Neoconservadurismo: modelo de la política cultural del Estado en la Zona

Metropolitana de Guadalajara

Las disyunciones recurrentes en la política cultural del Estado en la ZMG en materia de democracia están relacionadas con la genérica dualidad que se presenta enseguida, en donde el signo (/) representa esa disyunción:

\section{Participación ciudadana/no participación ciudadana}

De este grafo podemos inferir las asociaciones de sentido, identificadas con el símbolo ( | en el esquema de la siguiente:

\section{Formas de participar en la democracia}

Participación ciudadana
Participar

No pretendí en este trabajo describir otras posibles asociaciones de sentido con el grafo anterior; realicé solamente la decodificación de su significado "incluyéndole la formulación descriptiva de las 'totalidades' que las diversas contradicciones separan" (Hiernaux, en Suárez, 2008: 77). En el mismo grafo, los enunciados entrecomillados que se ubican arriba de los signos de disyunción significan esas totalidades.

A partir de la desestructuración del sentido "participación ciudadana" en contrasentido con "no participación ciudadana", podemos observar cómo en la cultura política del Estado en la ZMG -obviamente- el derecho persiste como 
uno de los principales referentes simbólicos, tanto de la democracia como la diversidad cultural. Los significados ajenos a estas fronteras son considerados como "ilegales" y "desordenados", "no ciudadanos"; los imaginarios ideales para ser integrados en la mentalidad de la democracia gubernamental. Otras formas de agruparse con sentido, que no juegan en el marco de los derechos y la participación social en las instituciones del Estado (las de la "no participación ciudadana"), son calificadas como "peores", contraviniendo el sentido de la democracia participativa. Para la política cultural del Estado, el símbolo del ciudadano y las organizaciones de la sociedad civil (OSC) son los tipos ideales "mejores" de la "participación ciudadana".

El contenido de la participación ciudadana de la política cultural del Estado tiene relación con el neoconservadurismo, el cual trata de mantener posiciones de poder y legitimidad, aunque el modelo de democracia esté "agotado" (De Sousa, 2002) en sus propias contradicciones. El discurso denota mejora, cohesión, derecho y libertad de acción, pero, en sí mismo, connota exclusión, centralidad y cinismo, al recalcar cuáles son los contenidos que valen más, justificando de esta forma la división social clasista que favorece a los que definen qué es la democracia. Este tipo de democracia que coquetea con el nuevo conservadurismo está bastante alejada de la idea de la democracia participativa o, en palabras de De Souza (2004: 53), de la

percepción de la posibilidad de la innovación entendida como participación ampliada de actores sociales de diferentes tipos en procesos de toma de decisiones [lo que implica] la inclusión de temáticas hasta entonces ignoradas por el sistema político, la redefinición de identidades y vínculos y el aumento de la participación, especialmente en el nivel local. 
Neoconservadurismo: modelo de la política cultural del Estado en la Zona

Metropolitana de Guadalajara

Volviendo con el "análisis estructural", para el caso de la cultura popular y tomando en cuenta que quienes construyen esa cultura son nombrados por las propias instituciones del Estado en los documentos oficiales como "artesanos", ${ }^{15}$ la disyuntiva queda representada como sigue:

\section{Artesano(a)/Artista}

A partir de esta dicotomía las asociaciones de sentido y las totalidades son:

Tipo de actores de la diversidad cultural

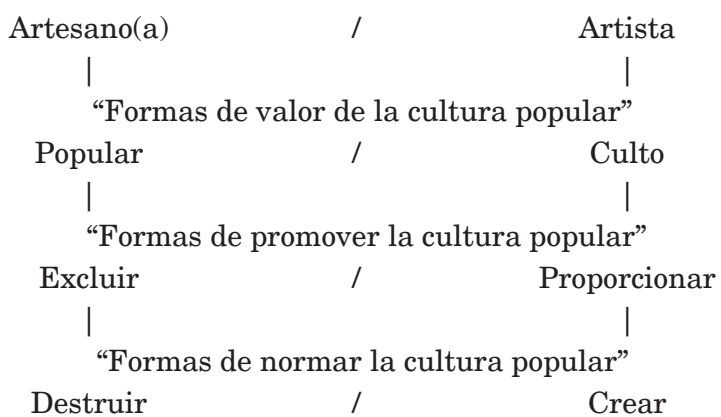

Como ha sucedido históricamente, el arte y los artistas son asociados con la opulencia de la clase social, con la ciencia y la técnica, con lo verdadero, con la superioridad racial; mientras que lo "popular" es todo lo contrario, es "lo peor", algo para "excluir" y "destruir" con el paso del tiempo, lo cual, dicho sea de paso, contradice los principios de la

15. Artesano(a) es un actor social de la cultura popular que produce y consume arte sin aparentemente pretender involucrarse en las formas de producción y consumo de las bellas artes. Cabe aclarar que la distinción entre "arte" y"artesanía" que estamos estableciendo es meramente analítica, lo que no significa que en ciertas prácticas y significados acerca del arte y la cultura estos dos términos y las prácticas con ellos asociadas se relacionen sin alterar su sentido, se nieguen al mismo tiempo o formen hibridaciones. 
diversidad cultural enunciados en la declaración emitida por la UNESCO (2001).

La política cultural del Estado menciona pocos apoyos monetarios y educativos para las y los "otros" en el discurso, pero no da cuenta de lo hecho para lograr la interculturalidad y el acceso al "desarrollo cultural". No obstante haya integración social para algunos/as artesanos/as de las sociedades no declaradas como "cultas", la valoración de los mismos es "negativa", considerando que la "alta cultura" se presenta en el discurso de forma hegemónica sobre la "no culta".

De forma planificada ("crear" y "proporcionar"), la política cultural del Estado apela a la mentalidad -propia del modelo neoconservador- que asimila y controla la diversidad cultural para no perder posiciones de poder. En sintonía con este modelo (que valora otras formas de pensar y hacer la política y la cultura como riesgos para la degradación intelectual, estética y social de las costumbres y la ideología dominante), el contenido de los documentos oficiales hace pensar que la cultura popular necesita ser capacitada y reconocida, invertir en su desarrollo, encubriendo el hecho de que la integración o el contacto de los artesanos con la elite artística y su cultura implica una relación de poder vertical y centralista, en favor de la "alta cultura"; en estas condiciones, empero, las aspiraciones para la diversidad cultural tienden a la homogeneidad y el intercambio competitivo, como se propone en el conservadurismo.

La diversidad cultural es la antítesis de la tradición del modelo conservador excluyente y opositor a lo distinto. La proclama del "fin de las ideologías", característica del neoconservadurismo, impide que la comunidad de artesanos/ as sea reconocida como sujeto con identidad particular, activos en los procesos de interculturalidad y con propuestas propias para satisfacer necesidades y resolver problemas comunes (lo que ampliamente se conoce como desarrollo). 
Neoconservadurismo: modelo de la política cultural del Estado en la Zona

Metropolitana de Guadalajara

Los contenidos son definidos por Hiernaux (en Suárez, 2008: 68) como "aquello que puede expresarse en los textos o en los discursos, es decir 'sentido', dicho de otro modo, 'maneras de ver las cosas' o tipos de sistemas de percepción”. La manera de ver las cosas en la cultura política del Estado en la ZMG es incoherente y conservadora. Los contenidos revisados aparentan el impulso de la democracia y la diversidad cultural, pero, por un lado, no hacen alusión a otras formas legítimas de participar en la política pública que sean ajenas a la participación ciudadana, reforzando así la habitual idea antidemocrática del Estado que gobierna sobre y en representación de la opinión de las y los ciudadanos. Por otro lado, el discurso continúa versando -como desde hace varias décadas- sobre la usual diferenciación desigual entre artistas y artesanos, en la que estos últimos se mantienen al margen del derecho a la cultura.

El sentido del discurso de la política cultural del Estado en la ZMG connota las "contradicciones" (Nivón, 2006a) y el "centralismo" (Castro de la Mora, 2010) de la política cultural de la federación y de Jalisco. Los contenidos revisados connotaron y denotaron el freno a los ideales de la democracia participativa y del reconocimiento de la pluralidad de culturas. La distinción entre lo universal y lo particular fue en el sentido de la imposición de lo universal a lo particular, pero no cualquier tipo de universalismo: uno conservador. La autonomía relativa de la cultura popular y de los "no ciudadanos" es "encubierta" en el plano discursivo, en relación de subordinación con el sentido atribuido a la "alta cultura" y a los artistas. La democracia se entiende como representatividad de unos cuantos sobre los "otros", un modelo de hacer política que se presenta como incuestionable y siempre progresista. 


\section{Conclusiones}

La cultura política y las estrategias de la política cultural del Estado en la ZMG durante el periodo 2010-2012 son análogas del modelo cultural neoconservador. ${ }^{16}$ Siguiendo a Muñoz (2005: 77), la "cosmovisión colectiva" y las "construcciones sociales" de las instituciones responsables del tema cultura provocaron legítimamente "el debilitamiento del orden democrático con el debilitamiento de la experiencia cultural". Lejos de enfrentar las contradicciones de la política pública nacional de otros periodos -identificadas por Nivón (2006a) - o de procurar la descentralización del poder estatal (Castro de la Mora, 2010), impulsaron la exacerbación de las contradicciones y la concentración del uso del poder.

La cultura política (cosmovisión colectiva) y las estrategias (construcciones sociales) de la política cultural de la ZMG son "retrogradas", injustas en un contexto multicultural, e inaceptables en el marco de la discusión contemporánea acerca de la democratización de la democracia. Se puede pensar que las instituciones del Estado están en una especie de reacomodo, utilizando la política cultural para mantener la legitimidad social y no perder las posiciones de poder, tal como lo propone el nuevo conservadurismo.

El análisis de contenido y la descripción de las estrategias de la política cultural del Estado en la ZMG mostraron que parece haber continuidad respecto de lo propuesto por la política cultural a nivel estatal y federal, por lo menos

\footnotetext{
16. En un análisis acerca de la música experimental en Jalisco, Pareyón (2010:8I) llegó a la conclusión que en la política cultural del Estado municipal había prácticas de "conservadurismo", como medio de "aplastamiento cultural". Al respecto comenta: "Guadalajara se cerró a la música experimental y comenzó a darle un peso excesivo a la polifonía clásica, considerada como único medio para hacer música. Esto aniquiló las pocas iniciativas para ventilar la cultura musical de la región e impidió un equilibrio estético e ideológico, necesario para la formación y desarrollo de ideas musicales locales" (en Gadea y Planter, 2010:8I).
} 
Neoconservadurismo: modelo de la política cultural del Estado en la Zona

Metropolitana de Guadalajara

durante la última década. Lo anterior significa discursos democratizadores y pluralistas pero acciones estratégicas para excluir, mantener el control del poder de las instituciones gubernamentales e invisibilizar la diversidad cultural.

Políticas y modelos culturales hay distintos, a nivel local, nacional e internacional. En Guadalajara, la democracia y la diversidad también están siendo impulsadas, pero desde otra perspectiva y otras estrategias, por movimientos como el de las escenas musicales ligadas con el metal extremo y el rap, cuyos seguidores cada semana organizan conciertos, además de llevar estaciones de radio, revistas y discos donde se proponen otras formas de usar el poder, de relacionarse y de entender el mundo. También son dignos de mencionarse los esfuerzos del movimiento lésbico, gay, bisexual, transgénero y heterosexual, el cual de a poco está minando los ideales y las prácticas conservadoras en Guadalajara.

El modelo cultural neoconservador de la política cultural del Estado en la ZMG no es omniabarcador y eterno, solamente es uno más en el universo de la ciudad, el cual puede en todo momento ser modificado. Tal vez esa sea la primera condición para que dicho modelo se transforme: aceptar que puede ser modelado por todos y todas; la segunda: investigarlo a fondo, dialogar sobre sus consecuencias y posibilidades, y proponer y desplegar alternativas.

Fecha de recepción: 03 de septiembre de 2012

Fecha de aceptación: 13 de marzo de 2014

Alonso, J. y J. M. Ramírez, 1997, La democracia de los de

Bibliografía abajo en México, UNAM/La Jornada/Consejo Electoral del Estado de Jalisco, Guadalajara.

Aziz Nassif, A. y J. Alonso, 2009, Una democracia vulnerada, CIESAS/Miguel Ángel Porrúa, México.

Estado 8 No. 60 
Eduardo Plazola

Bibliografía

Ayuntamiento de Guadalajara, 2010a, Informe de Actividades, en línea: http://cultura.guadalajara.gob.mx , 20 IOb, Plan de Desarrollo Municipal 201 0-20I 2, en línea: http://cultura.guadalajara.gob.mx , 20I I, Informe de Actividades, en línea:

http://cultura.guadalajara.gob.mx , 2012, Informe de Actividades, en línea:

http://cultura.guadalajara.gob.mx

Ayuntamiento de Tlajomulco, 2010a, Informe de Actividades, en línea: http://www.tlajomulco.gob.mx 20 I0b, Plan Municipal de Desarrollo 2010-20 I2, en línea: http://www.tlajomulco.gob.mx , 20I I, Informe de Actividades, en línea:

http://www.tlajomulco.gob.mx 20I2, Informe de Actividades, en línea:

http://www.tlajomulco.gob.mx

Ayuntamiento de Tlaquepaque, 2010a, Informe de Actividades, en línea: http://www.tlaquepaque.gob.mx $2010 b$, Plan Municipal de Desarrollo 20 I 0-20I 2, en línea: http://www.tlaquepaque.gob.mx , 20II, Informe de Actividades, en línea:

http://www.tlaquepaque.gob.mx , 20 I2, Informe de Actividades, en línea:

http://www.tlaquepaque.gob.mx

Ayuntamiento de Tonalá, 2010a, Informe de Actividades 2010, en línea: http://www.tonala.gob.mx 2010b, Plan Municipal de Desarrollo 20 I 0-20I 2 , en línea: http://www.tonala.gob.mx , 20I I, Informe de Actividades, en línea:

http://www.tonala.gob.mx , 2012, Informe de Actividades, en línea:

http://www.tonala.gob.mx

Ayuntamiento de Zapopan, 2010a, Informe de Actividades, en línea: http://www.zapopan.gob.mx 
Neoconservadurismo: modelo de la política cultural del Estado en la Zona Metropolitana de Guadalajara

en línea:

,2010b, Plan de Desarrollo Municipal 2010-2012,

http://www.zapopan.gob.mx

20I I, Informe de Actividades, en línea:

http://www.zapopan.gob.mx

,2012, Informe de Actividades, en línea:

http://www.zapopan.gob.mx

Castro, P. (coord.), 2005, Cultura política, participación y relaciones de poder, CONACYT/UAM/El Colegio Mexiquense A.C., México.

Castro de la Mora, O., 2010, La política cultural en Jalisco, Secretaría de Cultura Jalisco/Consejo Estatal para la Cultura y las Artes Jalisco, Guadalajara.

Castro, P. y H. Tejeda (coord.), 2009, Teoría y metodología para el estudio de la cultura política y el poder, Porrúa/ CONACYT/UAM, México.

De Souza, B. (coord.), 2004, Democratizar la democracia. Los caminos de la democracia participativa, Fondo de Cultura Económica, México.

Frisancho, S., H. Rivera y R. Mejía-Arauz, 2006, Investigar la diversidad cultural. Teoría, conceptos y métodos de investigación para la educación y el desarrollo, ITESO/Universidad de Colima/Universidad Iberoamericana, Guadalajara.

García, Canclini N. (ed.), 1987, Políticas culturales en América Latina, Grijalbo, México.

Mariscal, J. (comp.), 2007, Políticas culturales. Una revisión desde la gestión cultural, Universidad de Guadalajara, Guadalajara.

Muñoz, B., 2005, Modelos culturales. Teoría sociopolítica de la cultura, Anthropos/UAM, Barcelona.

Nivón, E., 2006a, La política cultural. Temas, problemas y oportunidades, CONACULTA, México.

, (coord.), 2006b, Políticas culturales en México: 2006-2020. Hacia un plan estratégico de desarrollo cultural, Universidad de Guadalajara/Porrúa, México. 
Eduardo Plazola

Bibliografía

Lozano, F., 2009, “Anatomía de la cultura en México”, Revista Folios. Publicación de discusión y análisis, núm. I3. Pp. 4-9.

Organización de las Naciones Unidas para la Educación, la Ciencia y la Cultura (UNESCO), 200I, Declaración Universal sobre la Diversidad Cultural, en línea: http://portal. unesco.org/es/ev.php-URL_ID=|3|79\&URL_DO=DO_ TOPIC\&URL_SECTION=20I.html

Pareyón, G., 2010, “Conservadurismo, negación y diáspora: Retrospectiva de la música experimental en Jalisco en los últimos cuarenta años", en H. Gadea y K. Planter (eds.), Jalisco en el Mundo Contemporáneo: Contribuciones a una Enciclopedia de la Época, Universidad de Guadalajara, Guadalajara, pp. 77-94.

Storey, J., 2002, Teoría cultural. Cultura popular, Ediciones Octaedro/Ediciones Universitarias de Barcelona, Barcelona.

Suárez, H. (coord.), 2008, El sentido y el método. Sociología de la cultura y análisis de contenido, El Colegio de Michoacán/ UNAM, México.

Todorov, T., 20I I, Nosotros y los otros, Siglo XXI, México.

Varela, R., 2005, Cultura y poder. Una visión antropológica para el análisis de la cultura política, Anthropos/UAM, Barcelona.

Zambrano, C., 2006, Ejes políticos de la diversidad cultural, Siglo del Hombre Editores/Universidad Nacional de Colombia, Bogotá. 